\title{
Concepciones ideológicas acerca del derecho en la obra de Cicerón ${ }^{1}$
}

\author{
JORGE DAVIDSON *
}

\begin{abstract}
RESUMEN
ABSTRACT

El análisis de De Legibus y De Re

The analysis of De Legibus and De Publica permite reflexionar acerca de la ideología en, relación al derecho, subyacente en la obra de Cicerón, principal representante del pensamiento

de los optimates. Partiendo de referenciales semióticos, las obras son abordadas con el objeto de determinar las estructuras de tipo lógico-semántico más básicas, para observar el lugar que ocupaba el derecho en la cosmovisión de los «mejores ciudadanos", así como comprender por
\end{abstract} qué las leyes eran consideradas como legitimas o ilegitimas.

\section{CONSIDERACIONES METODOLÓGICAS}

El presente artículo plantea un abordaje de las fuentes escritas a partir de la semiótica, enfoque poco utilizado en nuestra área, y que posee un

\footnotetext{
* Universidad Federal Fluminense. Río de Janeiro, Brasil.

Este trabajo forma parte de la investigación llevada a cabo en el marco de la Maestría en Historia Social de la Universidad Federal Fluminense.
} 
gran potencial, aún en desarrollo. Por lo tanto, resulta importante detenernos para realizar una breve descripción de la metodología empleada en nuestro análisis.

La lectura de las fuentes apunta a determinar la ideología que preside la creación de los textos. Tal como afirma Verón ${ }^{2}$, la ideología es un sistema de codificación de la realidad, y no un repertorio de mensajes codificados con ese sistema. Siendo así, explicar el modo en que un actor o una clase de actores sociales organiza significativamente la realidad, implica, desde el punto de vista de la comunicación, describir las condiciones que definen las relaciones de dichos actores con su mundo social. La ideología se torna así relativamente autónoma a la consciencia o intención de sus portadores, que pueden ser conscientes de sus puntos de vista, pero no de las condiciones semánticas (reglas y categorías de codificación) que los tornan posibles.

Principalmente seguimos el método de la sociología estructuralista genética de la literatura, desarrollado por Lucien Goldmann ${ }^{3}$. Este autor, construye su método a partir de cinco premisas básicas. La primera afirma que la relación esencial entre la vida social y la creación literaria no tiene que ver con el contenido de dichos sectores de la realidad humana, sino sólo con las estructuras mentales, o sea, las categorías que organizan tanto la conciencia empírica (real) de un determinado grupo social, como el universo imaginario que el escritor crea.

La segunda premisa sostiene que, si bien la naturaleza del sujeto que conoce, no es ni solamente individual, ni solamente colectiva, y sí una estructura muy variable en la que intervienen individuos y grupos, las estructuras mentales antes mencionadas (o estructuras categoriales significativas) no son fenómenos individuales sino sociales.

La tercera premisa afirma que la relación entre la estructura de la consciencia de un grupo social, y la del universo imaginario de la obra de ficción es, en el mejor de los casos, de homología estructural; aunque puede también no pasar de una relación significativa, pero leve (por ejemplo funcional).

En cuarto lugar, las estructuras mentales son las que confieren a la obra literaria su unidad, siendo por ello uno de los elementos más importantes de su calidad estética y literaria.

2 Verón, Eliseo, ldeología, estrutura, comunicação. São Paulo: Cultrix, 1977. Pág. 85.

3 Goldmann, Lucien, Marxismo y ciencias humanas. Buenos Aires: Amorrortu, 1975. 
Y por último, la quinta premisa dice que las estructuras mentales, traspuestas al universo ficcional creado por el escritor, son no conscientes. Por lo tanto, nunca podrán ser alcanzadas por un estudio literario inmanente, ni orientado a las intenciones conscientes del autor o a la psicología profunda.

El método consiste en la utilización de dos niveles de análisis para abordar una determinada obra literaria: la explicación y la comprensión. La comprensión implica el descubrimiento de una estructura significativa inmanente a la obra estudiada: se trata de un problema de coherencia interna que exige tomar al pie de la letra el texto, todo el texto y nada más que el texto, y buscar en el interior de éste una estructura significativa global. La explicación es la inserción de dicha estructura como elemento constitutivo y funcional de una estructura mayor inmediatamente englobante, la de la consciencia de clase.

Siguiendo a Cardoso ${ }^{4}$ hemos usado otros métodos específicos para analizar la estructura inmanente a las obras, aclarando que los mismos son considerados complementarios y subordinados, con respecto al método de Goldmann.

Recurrimos al método de lectura isotópica, desarrollado por Algirdas Greimas ${ }^{5}$, para analizar la estructura significativa, en lo que se refiere al aspecto semántico. Las categorías semánticas isotópicas permiten pasar de la significación presente en cada frase o enunciado aislado (microsemántica) a la significación del discurso completo (macrosemántica). De este modo, es posible resolver las ambigüedades presentes en los textos, para tratar de aproximarnos a una lectura única de los mismos.

Los resultados obtenidos a partir de la lectura isotópica fueron volcados en un cuadrado semiótico. Elaborado también por Greimas, el cuadrado semiótico constituye una representación gráfica de la articulación de una categoría semántica en un discurso dado, del cual es su estructura profunda, el núcleo de sentido.

\section{EL DERECHO EN LA ROMA TARDOREPUBLICANA}

Durante el período considerado se produjo un importante crecimiento y diferenciación en el ámbito del derecho. Hopkins ${ }^{6}$ utiliza, en su análisis de

CARdoso, Ciro F. Narrativa, sentido, historia. São Paulo: Papirus, 1997.

Cf. Greimas, A. J. y Courtés, J., Dicionário de Semiótica. São Paulo: Cultrix, 1989.

6 Cf. Hopkins, K., Conquerors and slaves. Cambridge: Cambridge University Press, 1978. 
la sociedad romana tardo-republicana, el concepto estructural de diferenciación. A medida que las sociedades se complejizan, dice este autor, algunas instituciones se destacan y adquieren mayor especificidad funcional. Dichas instituciones, recientemente emergidas, construyen su identidad a través de normas y valores específicos, y sus miembros compiten con otros grupos sociales por los recursos

La evolución del derecho hacia fines de la República (junto a la del ejército, el otro ejemplo más notable), confirmaría su lugar entre las instituciones que se incluyen en este proceso de diferenciación. A finales del siglo I a. C., se habían creado en Roma instituciones nuevas, un lenguaje jurídico; tribunales especializados; un vasto cuerpo de derecho y de procedimientos; libros de opiniones jurídicas; etc.

De todos modos, no debemos perder de vista el hecho de que la clase propietaria fue la única autora y responsable de la actividad legislativa ${ }^{7}$, constituyendo uno de sus principales fines el mantenimiento de su posición como clase hegemónica. En tal sentido, desarrolló el derecho pari passu con las necesidades del Estado, en la mayoría de las ocasiones, identificadas con sus propios intereses de clase. El sistema legal tenía a su cargo la legitimación del sistema social de propiedad, así como el establecimiento de sanciones para punir las transgresiones, constituyendo uno de los mecanismos fundamentales para generar y reproducir la desigualdad.

\section{LOS FUNDAMENTOS RELIGIOSOS DEL DERECHO}

La religión romana, a diferencia de las religiones occidentales de la actualidad, se basaba en rituales públicos íntimamente vinculados con la actividad estatal. Sobre todo, la religión se encontraba presente en las actividades políticas y militares. Los dioses romanos no eran figuras preocupadas exclusivamente con cuestiones morales. Por el contrario, estaban presentes en las actividades del estado: en las guerras, en las asambleas. Los mecanismos religiosos que podían detener la actividad política (días nefastos, augurios) no deben ser considerados meramente como instrumentos de dominio: los políticos parecían estar convencidos de que los dioses apoyaban sus planes, a la vez que los consideraban enfrentados a aquellos que se les oponían. Esto explica la presencia de lo religioso en el enfrentamiento político, sobre todo a fines del período republicano.

7 Cf. CASCAREJo, Juan, Escritura, oralidad e ideología. Hacia una reubicación de las fuentes escritas para la historia antigua, Gerión 11, Madrid, 1993. 
En sus orígenes, el derecho romano ${ }^{8}$ estaba íntimamente ligado a la religión. La idea de una oposición claramente marcada entre fas y ius (términos relacionados con el derecho sagrado y profano respectivamente) debe ser descartada para el período republicano, ya que el surgimiento de un derecho laico fue fruto de un lento proceso de des-sacralización que recién concluiría en tiempos del Imperio. Los nombres de los grandes jurisprudentes republicanos confirman que se mantuvo de facto la antigua relación entre la ciencia de la ley y el sacerdocio ${ }^{9}$.

El término fas, de raíz indoeuropea, representaba una realidad invisible, una base religiosa sin la cual la existencia del derecho era imposible. Se refería a lo sagrado, a la norma religiosa que ordenaba las relaciones entre los hombres y los dioses, significando lo no-prohibido, aquello que la religión consideraba lícito, no nefasto (nefas). Como momento en el tiempo, daba o dejaba de dar a las acciones de los hombres la base mística que constituía la posibilidad de alcanzar el éxito ${ }^{10}$. En virtud de su carácter sagrado, no podía ser discutido.

Por su parte, el término ius expresaba la idea de integridad y perfección. En Roma existía una noción concreta del ius: demarcaba el área de actividades y pretenciones resultantes de la delimitación de un estatuto personal o colectivo. El ius delimitaba los deberes y atribuciones de acuerdo al lugar que cada hombre ocupaba en la sociedad. Consecuentemente, el ius de cada individuo estaba en conflicto con el de los otros, y de la reglamentación de estos múltiples iura surgía el derecho.

El ius debía necesariamente tomar en consideración al fas, esto es, el orden del mundo: nada podía existir sin estar de acuerdo con un orden superior. En De Legibus (2.4.8) Cicerón expresa:

«Bien, entonces creo que ha sido la opinión de los hombres más sabios que la Ley no es un producto del pensamiento humano, ni es ninguna promulgación de los pueblos, sino algo eterno que rige el universo entero mediante su sabiduría para ordenar y prohibir." ("Hanc igitur video sapientissimorum fuisse sententiam, legem neque hominum ingeniis excogitatam nec scitum aliquod esse populorum, sed aeternum quiddam, quod universum mundum regeret imperandi prohibendique sapientia.")

8 El término derecho romano se circunscribe en este artículo al período Republicano, siendo que tradicionalmente suele referirse a la consolidación realizada en tiempos del imperio, en los siglos III y IV d.C.

9 Cf. Zulueta, F. de, A ciência do direito, in Bailey, Cyril (Org.), O legado de Roma. Rio de Janeiro: Imago Editora, 1992.

10 Cf. MesLin, M. L'homme Romain-Des origenes au / siècle de notre ère. Bruselas: Editions Complexe, 1985. 
Para los romanos, entonces, el derecho era a la vez el conjunto de las relaciones que vinculaban a los hombres con los dioses, y las que vinculaban a los hombres entre sí.

\section{MARCO TULIO CICERÓN}

Marco Tulio Cicerón nació en Arpinum, en la región de Italia central, en el 106 a.C. Proveniente de una familia aristocrática local, accedió al Consulado en el año 63 a.C., transformándose en un «hombre nuevo» (novus homo), nombre con el que los romanos denominaban a aquellos individuos de la clase ecuestre que lograban ingresar al Senado, luego de ocupar el más alto cargo del cursus honorum. Su carrera exitosa se debió principalmente a su dominio de la oratoria y la retórica en el ámbito de los tribunales, llegando a ser considerado el orador más destacado de su época, y tal vez de toda la historia de Roma.

Cicerón recibió una educación política temprana, asistiendo habitualmente al Senado y estableciendo contacto personal con los más grandes oradores políticos del momento: Lucio Craso (140-91 a.C.) y Marco Antonio (143-87 a.C.). Posteriormente, estudió oratoria y filosofía en Rodas y Atenas. Desde el año 80 a.C., en que realizó la defensa de su primer caso, se destacó en su tarea de abogado, y también como divulgador y adaptador de las ideas filosóficas griegas, principalmente las de los filósofos estoicos.

Representante del poder del Senado, la extensión y el contenido de su obra resultan indispensables para analizar la ideología de la clase dominante con respecto al derecho, y dentro de este grupo, la de los optimates, que el mismo Cicerón definía como "aquellos que no son criminales, que no carecen de principios por naturaleza, que no son revolucionarios salvajes ni están afectados por dificultades financieras» (Pro Sestio, 97).

Cicerón era un defensor de la política del concordia ordinum, acuerdo entre todos los grandes propietarios de tierras pertenecientes los órdenes senatorial y ecuestre; y estaba enfrentado a aquellos políticos conocidos como populares, a los que calificaba como demagogos y enemigos de la República. Su meta era el mantenimiento a cualquier costo del orden establecido, lo que lo llevaba a considerar a los que se oponían a su modelo de sociedad como sediciosos y carentes de moral ${ }^{11}$. drid, 1994. 
Entre el 52 y el 49 a.C. gobernó la provincia de Cilicia. Luego de haber apoyado a Pompeyo, su postura se tornó profundamente reaccionaria, defendiendo a ultranza los intereses de la nobilitas. Derrotado Pompeyo por los seguidores de César, en la batalla de Farsalia (48 a.C.), debió abandonar la vida política hasta la muerte de éste, en el 44 a.C. A su regreso a la arena política, intentó atraer a Octavio hacia la causa republicana y senatorial. La constitución del segundo triunvirato en el 43 a.C. causó el fracaso de dicha política y lo llevó a su muerte.

\section{LA INFLUENCIA DEL PENSAMIENTO ESTOICO}

Tal como afirmamos anteriormente, Cicerón se destacó por adaptar y difundir las ideas filosóficas griegas en el mundo romano. Entre estas, tiene especial relevancia el estoicismo, una de las fuerzas intelectuales más poderosas con las que los romanos entraron en contacto a partir de la conquista.

La evolución de esta corriente filosófica puede ser dividida en tres grandes períodos:el estoicismo antiguo (segunda mitad del siglo IV hasta inícios del siglo II a.C.); el estoicismo medio (siglos II y I a.C.); y el estoicismo nuevo (a partir del siglo I d.C.).

Nos detendremos brevemente en los principales puntos que conformaron la doctrina estoica original, sólo para poder observar cuáles fueron los cambios que se produjeron durante el período que nos ocupa. El estoicismo original, entre cuyos creadores se destaca Zenón de Cittium (336-264 a.C.) estaba fuertemente influído por las ideas cínicas, al punto de que algunos investigadores las llegaron a unificar, denominándolas doctrinas cínico-estoicas.

Tal como afirma Puente Ojea, el núcleo del estoicismo se encontraba marcado por una actitud radical de la voluntad: la decisión de asumir el dolor, de anular el mal y sus causas, como parte del orden (kósmos), y de insertarse mediante la voluntad en la totalidad del universo. De este modo, negaba el mundo hostil incorporándolo, invirtiendo la relación dialéctica sujeto-mundo y, por lo tanto, abandonando la conducta agónica y la resistencia militante del voluntarismo cínico. A partir de estas premisas, se originó una forma de apátheia que consistía en asumir la realidad distanciándose de ella ${ }^{12}$.

12 Cf. Puente OJeA, Gonzalo. Ideología e historia. El fenómeno estoico en la sociedad antigua. Madrid: Siglo XXI, 1974. Págs. 83-84. 
Una de las características salientes era la idea de la existencia de un universo, un kósmos organizado del que los individuos formaban parte, y que era concebido como un ser vivo. Distanciado de la actividad social y política, el estoicismo antiguo no justificaba ninguna forma particular de ciudad ni de gobierno. El ideal de la kosmópolis conducía a la idea de que los hombres no debían vivir en estados separados: todos debian ser conciudadanos formando parte de una concordia universal (homónoia).

La periodización que definimos al principio de este punto, se corresponde con los cambios que fue sufriendo el pensamiento estoico en el tiempo. Estos se debieron tanto a los aportes que los sucesivos pensadores fueron haciendo a la doctrina, como a las profundas alteraciones que se produjeron en las estructuras políticas, económicas y sociales del mundo greco-romano.

Para el estoicismo medio, que comprende a los siglos II y I a.C, el contacto con el mundo romano fue de importancia decisiva. Si los romanos se sintieron atraídos por la gravitas y la auctoritas inherentes a esta corriente filosófica, los pensadores de la Estóa Media demostraron que «estaban dispuestos a atemperar y adaptar sus enseñanzas éticas y politicas a las pautas y postulados de los estadistas y soldados romanos con los que entraron en contacto" ${ }^{13}$.

Panecio de Rodas (185-109 a.C) fue la figura que más se destacó en esta adecuación de las ideas estoicas al mundo romano. Procedente de una familia noble, este pensador estableció estrechas conexiones con la aristocracia de Roma, llegando a formar parte del círculo más íntimo de Escipión Emiliano. Panecio participó activamente en la adaptación del legado estoico a los intereses de la clase dominante romana introduciendo "la creencia en la posibilidad del progreso moral de las masas y de la encarnación del ideal de justicia en la res publica» ${ }^{14}$.

El distanciamiento contemplativo de la realidad va a ser rechazado por Panecio, disolviendo definitivamente los vínculos que el estoicismo tenía con el cinismo, y que resultaban inaceptables para la aristocracia romana. Rechazando el intelectualismo de Crisipo, Panecio afirma que el hombre es un organismo unitario, en el que el cuerpo juega un importante papel. Al lado del impulso primero y los instintos, reconoce la existencia de una tendencia en la que se asocian la naturaleza y la razón. Desarrollada por la razón, esta tendencia da origen a las virtudes: sabiduría; prudencia

13 Barker in Puente OJea. Op. cit.

14 Puente OJeA, Gonzalo. Op. cit., pág. 135. 
práctica; justicia; valor, y junto con él, la grandeza del alma; equilibrio; moderación; armonía ${ }^{15}$. Esta nueva actitud, iba a desembocar en la condena del intelectualismo, que sería reemplazado por una concepción pragmática de la vida moral. El hombre, entonces, no debía huir contemplativamente del entorno cívico, sino que tenía que imitar el ejemplo de rectitud moral de los ciudadanos honestos. Por lo tanto, cobró primacía la actividad político-práctica al servicio de la colectividad. La idea de una sociedad natural pasó de la kosmópolis al estado concreto, que limitaba la vida personal del individuo y exigía su adhesión moral ${ }^{16}$.

El modelo de excelencia moral ya no se correspondería con el intelectual contemplativo sino con el estadista romano, personaje que servía a la comunidad distinguiéndose por ello. En esta línea de pensamiento, Posidonio, discípulo de Panecio, concebió la idea de la existencia de una armonía general entre el cielo y la tierra, en la que el gobierno terrenal sería una copia del celestial. Los filósofos y estadistas debían imitar en la tierra a esta república divina, y a su muerte, serían transferidos a ella. Estos desarrollos teóricos, irían a dar sustento a la idea de la hegemonía romana como un factor del orden cósmico, en la que los estadistas cumplían un papel de concordia ecuménica, y por lo tanto servían a la voluntad de los dioses. Como veremos a continuación, estos desarrollos teóricos se encuentran visiblemente presentes en las obras analizadas.

\section{EL DERECHO EN DE LEGIBUS Y DE RE PUBLICA}

Nuestro análisis se basará en los tratados De Legibus y De Re Publica. Siguiendo los pasos de Platón, en De Re Publica, Cicerón aborda diversos tópicos como la discusión acerca de la mejor forma de gobierno; la justicia; el hombre de estado ideal; y la educación, entre otros. Presentado en forma de diálogo, fue considerado por su autor como una obra escrita en forma lenta y dificultosa, y no simplemente como una transferencia de ideas griegas al mundo romano, como algunos de sus trabajos filosóficos posteriores. Lamentablemente, De Re Publica ha llegado hasta nosotros en forma fragmentada.

De Legibus puede ser visto como una secuela de De Re Publica. Tal como expresa el texto: "Pero si me preguntas que espero de $t i$, considero

15 Michel in PARein, Brice (director). Historia de la filosofía. Del Mundo Romano al islam medieval (vol. 3). Madrid: Siglo XXI, 1972.

16 Puente Ojea, Gonzalo. Op. cit., pág. 149. 
lógico que, puesto que ya has escrito un tratado acerca de la constitución del Estado ideal, deberías escribir también uno acerca de sus leyes" (De Leg., 1.5.15).

La opinión más aceptada es que la obra constaba de seis libros, de los cuales han llegado a nosotros sólo los primeros tres. Escrito al igual que De Re Publica, en forma de diálogo, los principales temas abordados por el tratado son la ley y la justicia en general; las leyes religiosas; el rol del estadista con respecto las leyes; y los poderes legislativos, ejecutivos y judiciales del Estado.

Para comenzar, en los textos analizados subyace la idea de la existencia de un orden cósmico, que es preciso mantener en equilibrio. Los dioses habrían dispuesto dicho orden de acuerdo con la naturaleza, y por lo tanto se trataría de un orden inmutable y eterno. La supremacía de los optimates se encontraba considerada en la naturaleza: "ciertamente la seguridad del Estado depende de la sabiduría de sus mejores hombres, especialmente desde que la Naturaleza ha dispuesto, no sólo que esos hombres que son superiores en virtud y en espiritu deban guiar a los más débiles, sino también que los débiles deben ser deseosos de obedecer a los más fuertes» (De Re Pub., 1.34.51) ( «certe in optimorum consiliis posita est civitatium salus, praesertim cum hoc natura tulerit, not solum ut summi virtute et animo preaeessente inbecillioribus, sed ut hi etiam parere summis vellent").

En las obras analizadas se puede constatar que la ley se presenta como algo perteneciente, en última instancia, al ámbito del fas, esto es, que está inscripta en el orden del universo. Según Cicerón (De Legibus, 2.4.10), "la Ley verdadera y fundamental aplicada al comando y a la prohibición es la razón correcta del supremo Júpiter» («[...] quam ob rem lex vera atque princeps apta ad iubendum et ad vetandum ratio est recta summi lovis").

De acuerdo con nuestra interpretación, Cicerón considera que entre los hombres, existen algunos que poseen una razón e inteligencia superior (sabiduría), cualidades que los aproximan más a los dioses. De este razonamiento se desprende la idea de que sólo dicho grupo de ciudadanos (los boni, los optimates) estaría capacitado para dictar leyes verdaderas, de acuerdo con la Naturaleza y respetando el orden del universo.

Tal como indica Goldmann, las obras literarias tienen una función parcialmente crítica que, al generar un universo rico y múltiple de personajes y situaciones, es también llevada a presentar, por razones literarias y estéticas, las posiciones que su visión de mundo rechaza (imprescindibles para que el autor pueda expresarse a favor de las actitudes y comportamientos 
que defiende). En este sentido, resulta interesante verificar cuáles, entre las diversas situaciones históricas que encarnan las posiciones antagónicas que él condena, son percibidas como especialmente importantes.

Aparecen entonces, aquellas leyes dictadas por la multitud (plebs), que deben ser consideradas ilegítimas si se oponen a este orden supra humano al que nos referimos. En De Legibus 2.5.13, Cicerón afirma que este tipo de leyes "no merecen más ser llamadas leyes, que las reglas que una banda de ladrones pudiera pasar en su asamblea" ("quae non magis legis nomen atgintum, quam si latrones aliquas conssesu suo sanxerint»). Una de las pruebas de que no se trata de verdaderas leyes estaba dada por el hecho de que el Senado podía derogarlas ( «[...] el Senado las revocó con un fallo y en un único momento". "[...] quae praesertim uno versiculo senatus puncto temporis sublatae sint». De Leg., 2.5.14).

Por lo tanto, queda de manifiesto que, para Cicerón, el Senado debía dominar tanto la política en general como el dictado de las leyes (lo que se garantizaría a través de los senatum consultum y la previa aprobación de las leyes a ser presentadas ante la Asamblea).

El gráfico 1 presenta la estructura semántica de los textos analizados, con respecto a la ley. De acuerdo con nuestra visión, los boni representan para Cicerón el vínculo entre lo divino y lo humano. Esto resulta evidente si observamos que la clase dominante, era también la que cumplía el rol de mediadora entre los hombres y los dioses. Esta mediación se llevaba a cabo a través de las funciones religiosas que cumplían los magistrados, los sacerdotes, y el mismo Senado. No es casual que en el conflicto patricio-plebeyo, la inclusión de estos últimos en los colegios sacerdotales (ley Ogulnia, 300 a.C.) haya sido una de las últimas concesiones del grupo dominante.

Antes de abordar el análisis mediante el método de lectura isotópica, resulta importante destacar que ningún método es aplicado «inocentemente": de hecho, nuestras hipótesis de trabajo orientan la aplicación metodológica. Esto implica que debemos desechar la idea de que existen estructuras "correctas» a ser halladas, con independencia de las hipótesis de las que se parta.

A través de la lectura isotópica hemos hallado dos redes temáticas que se oponen. En ambas redes, los elementos figurativos se refieren a la existencia de un orden cósmico en el que se encuentra consagrada la supremacía de los boni. La legitimidad o ilegitimidad de las leyes depende de si las mismas respetan y sustentan dicho orden cósmico, o si se le oponen, intentando subvertirlo. 
Gráfico 1. Esquema semántico de la concepción del derecho en De Legibus y De Re Publica

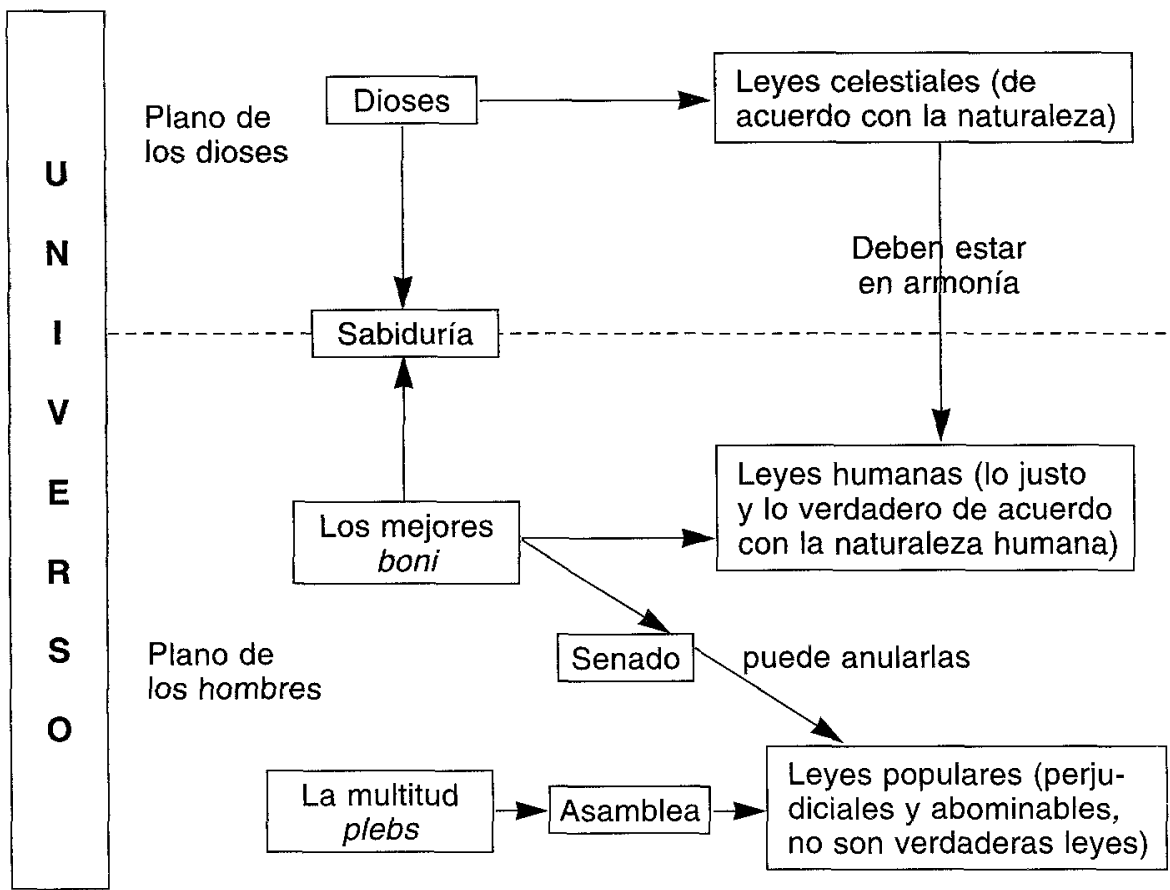

Red temática 1

\begin{tabular}{|c|l|c|}
\hline $\begin{array}{c}\text { Elementos } \\
\text { temáticos } \\
\text { principales }\end{array}$ & Elementos figurativos & $\begin{array}{c}\text { Elementos } \\
\text { axiológicos } \\
\text { relacionados }\end{array}$ \\
\hline Leyes legitimas & $\begin{array}{l}\text { «la ley verciadera es la razón justa de acuerdo con } \\
\text { la naturaleza» (De Re Pub., 3.22.33) / «es un peca- } \\
\text { do tratar de alterar esta ley, ni es permitido rechazar } \\
\text { alguna parte de ella, y es imposible abolirla entera- } \\
\text { mente» (De Re Pub., 3.22. 33) / «Porque el univer- } \\
\text { so obedece a Dios; los mares y las tierras obedecen } \\
\text { al universo; y la vida humana está sujeta a los de- } \\
\text { cretos de la Ley supremia» (De Leg., 3.2.4) / «la Ley } \\
\text { es la distinción entre las cosas justas e injustas } \\
\text { hecha de acuerdo con la primera y más antigua de de al orden } \\
\text { todas las cosas, la Naturaleza» (De Leg., 1.5.13) } \\
\text { "la Ley cuya naturaleza he explicado no puede ser } \\
\text { rechazada ni derogada» (De Leg., 2.5.14)/ }\end{array}$ & Rónico \\
\hline
\end{tabular}


Red temática 2

\begin{tabular}{|c|c|c|}
\hline $\begin{array}{l}\text { Elementos } \\
\text { temáticos } \\
\text { principales }\end{array}$ & Elementos figurativos & $\begin{array}{l}\text { Elementos } \\
\text { axiológicos } \\
\text { relacionados }\end{array}$ \\
\hline Leyes legítimas & $\begin{array}{l}\text { "Estas no merecen más ser llamadas leyes que las } \\
\text { reglas que una banda de ladrones pueda pasar en } \\
\text { su asamblea" (De Leg., 2.5.13) / "Tampoco en una } \\
\text { nación puede un estatuto de cualquier tipo ser lla- } \\
\text { mado Ley..." (De Leg., } 2.5 .13 \text { ) / «... el Senado las } \\
\text { rechazó con una sentencia y en un único momento" } \\
\text { (De Leg., } 2.5 .14 \text { ) / "Pero, si tanto poder pertenece a } \\
\text { las decisiones y decretos de tontos que las leyes } \\
\text { de la naturaleza pueden ser cambiadas por sus } \\
\text { votos, entonces por qué no pueden ordenar que lo } \\
\text { que es malo y funesto debiera ser considerado } \\
\text { bueno y saludable?" (De Leg. } 1.16 .44 \text { ) / "Pero la } \\
\text { noción más tonta de todas es la creencia de que } \\
\text { todo lo que se encuentra en las costumbres o las } \\
\text { leyes de las naciones es justo" (De Leg. 1.14.42) }\end{array}$ & $\begin{array}{l}\text { Subversión de } \\
\text { orden cósmico }\end{array}$ \\
\hline
\end{tabular}

Las redes temáticas halladas en nuestro análisis utilizando el método de lectura isotópica pueden ser volcadas en el siguiente cuadrado semiótico:

S1

Orden cósmico

(deseable-útil)

«... algún poder debe ser garantizado a los mejores ciudadanos...» «... la Ley es una fuerza natural..." / «... Una eterna e inmodificable ley...»/ «... el Estado depende de la sabiduría de sus mejores hombres...»/ «... el dominio ha sido garantizado por la naturaleza a todo lo que es mejor..."
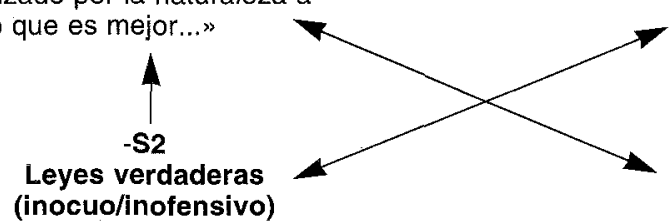

«... la Ley verdadera es la razón correcta de acuerdo con la naturaleza...» / «... la Ley es una fuerza natural...» «... es la distinción entre cosas justas e injustas hecha de acuerdo con ... la Naturaleza» / «... no puede ser revocada ni anulada.»
S2

\section{Leyes falsas} (nocivo)

«Estas no merecen ser llamadas leyes, más que las reglas que una banda de ladrones pueda pasar en su asamblea» / «tampoco en una nación un estatuto cualquiera puede ser llamado ley»<smiles>C1C[SiH2][SiH2]1</smiles>

Desorden Cósmico (indeseable) «... si tanto poder pertenece a los decretos y decisiones de tontos, de tal modo que las Leyes de la naturaleza puedan ser cambiadas...» 
En el cuadrado semiótico elaborado, el recorrido valorizado es S2 $\rightarrow$-S2 $\rightarrow \mathrm{S} 1$, que conduciría a mantener el orden del universo. La deixis positiva es euforizada ("orden», "correcto», "verdadera», "eterna», etc.) y la deixis negativa es disforizada («funesto», «tontos», "banda de ladrones», etc.).

En lo que se refiere a la relación entre la visión acerca de la ley, tal como queda de manifiesto en las obras analizadas, y la ideología de los optimates, podemos concluir que existe una relación de funcionalidad. Las obras de Cicerón refuerzan la idea de la supremacía de un grupo que, ajustándose al orden divino, ejerce el control político, y ostenta el monopolio para la determinación de que leyes son justas y que leyes son subversivas.

Las desigualdades entre los ciudadanos son consideradas por Cicerón como pertenecientes al fas. Por este motivo, el mantenimiento de la supremacía de los "mejores ciudadanos" se anteponía inclusive al cumplimiento de las leyes, consideradas según su origen como legítimas o ilegítimas.

Ante el conflicto de dos principios (leyes, consideradas ilegítimas, y el orden cósmico que proclamaba la superioridad de los boni), la violencia va a ser justificada como medio para el mantenimiento de la superioridad. Por esto, no debería sorprendernos que un gran conocedor de la ley, como Cicerón, presente contradicciones en lo que al respeto por la ley se refiere. Si bien al enunciar las leyes deseables para un Estado, defiende el derecho de que la pena de muerte no pueda ejecutarse sin la mediación de un juicio ante el pueblo ( $D e$ Leg., 3.3.6), al opinar acerca del intento reformista de Tiberio Graco (133 a.C.), defiende a los grandes poseedores del ager publicus, y aún comenta aprobatoriamente la acción represiva de Escipión Nasica, desconsiderando la evidencia de que ambos hechos violaban claramente la legislación vigente.

Las concepciones acerca del orden del universo que aparecen en las obras analizadas resulta sumamente funcional al dominio de una elite que se adjudicaba el rol de intermediaria entre el mundo de los dioses y el de los hombres y que, al mismo tiempo, era guardiana del orden cósmico que contemplaba su superioridad. 